\title{
Post-challenge blood glucose concentration and stroke mortality rates in non-diabetic men in London: 38-year follow-up of the original Whitehall prospective cohort study
}

\author{
G. D. Batty • M. Kivimäki • G. Davey Smith • \\ M. G. Marmot • M. J. Shipley
}

Received: 9 November 2007 / Accepted: 17 March 2008 / Published online: 26 April 2008

(C) The Author(s) 2008

\begin{abstract}
Aims/hypothesis While individuals with diabetes have a raised risk of stroke, it is unclear whether hyperglycaemia in non-diabetic populations is related to the development of this disease.

Methods In this prospective cohort study of 19,019 men, capillary blood was drawn $2 \mathrm{~h}$ after consumption of a glucose preparation equivalent to $50 \mathrm{~g}$ of anhydrous dextrose. Study participants were then followed for mortality for a maximum of 38 years.

Results During follow-up of 18,406 non-diabetic men, 13,116 deaths occurred (1,189 by stroke). Plots of stroke mortality rates versus blood glucose identified an upward inflection in risk of death from stroke at about $4.6 \mathrm{mmol} / \mathrm{l}$. This upward inflection in risk could be adequately described using a single linear term above this threshold. A $1 \mathrm{mmol} / \mathrm{l}$ increase in blood glucose after this point was associated with a $27 \%$ increase in risk of death from stroke (hazard ratio $1.27,95 \% \mathrm{CI} 1.14-1.42$ ). This increase in risk was partially attenuated by adjustment for covariates (1.17,
\end{abstract}

G. D. Batty $(\bowtie)$

MRC Social and Public Health Sciences Unit,

University of Glasgow,

4 Lilybank Gardens,

Glasgow G12 8RZ, UK

e-mail: david-b@sphsu.mrc.ac.uk

M. Kivimäki • M. G. Marmot • M. J. Shipley Department of Epidemiology and Public Health, University College London,

London, UK

G. Davey Smith

Department of Social Medicine, University of Bristol, Bristol, UK
1.04-1.31) but remained statistically significant at conventional levels. Similar observations were made when allcause mortality was the outcome of interest, although the magnitude of the association with blood glucose was somewhat lower.

Conclusions/interpretation An incremental elevation in stroke mortality rates occurs with increasing post-challenge blood glucose.

Keywords Blood glucose $\cdot$ Mortality $\cdot$ Stroke $\cdot$ Whitehall

\section{Introduction}

Several population-based cohort studies have shown that individuals with diabetes have an elevated risk of stroke relative to people who are diabetes-free [1]. However, it is unclear whether hyperglycaemia in non-diabetic populations is also related to the development of stroke: while some investigators found no relationship between blood glucose and stroke risk [2, 3], others have reported increased rates which are confined to the upper end of the blood glucose spectrum $[1,4,5]$.

This apparent discordance in findings may be at least partially explained by the low number of stroke events in some studies which limits statistical power. For instance, in a recent meta-analysis of ten European cohort studies with individual person data [6], there were fewer than 200 stroke deaths in men, too small a number to reliably examine the shape of the relationship between blood glucose and stroke mortality rates in those who were non-diabetic. This was also the case in a 10-year follow-up of the Whitehall cohort study, where only 69 deaths had occurred in diabetes-free men [7]. With more than 1,100 stroke deaths having occurred in the intervening 25 years, we now have much 
greater statistical power with which to explore this association.

\section{Methods}

Data were collected on 19,019 male government employees aged from 40 to 69 years when examined between 1967 and 1970, representing a 74\% response [8]. Data collection involved the completion of a study questionnaire and participation in a medical examination, both of which have been described in detail elsewhere [8]. In brief, data on civil service employment grade (an indicator of socioeconomic position), intermittent claudication, angina, chronic bronchitis, marital status, physical activity, cigarette smoking, height, weight, forced vital capacity, ischaemia, fasting plasma cholesterol and blood pressure were all determined using standard protocols. Body mass index was computed using the usual formula, that is, weight/height ${ }^{2}\left(\mathrm{~kg} / \mathrm{m}^{2}\right)$.

After an overnight fast, capillary blood was drawn $2 \mathrm{~h}$ after consumption of a glucose preparation equivalent to $50 \mathrm{~g}$ of anhydrous dextrose. Blood sugar concentration was estimated using the ferricyanide reduction micromethod on an autoanalyser (Technicon method N-9a) [8]. For the study period (late 1960s) this was a standard protocol for determining blood glucose levels, as evidenced by other cohort studies from the same era [9-11]. However, to interpret our findings, it is necessary to point out that the blood glucose test was non-standard in several respects: (1) it was post-challenge; (2) the challenge itself (50 g) was lower than has been used elsewhere (75 g); (3) capillary rather than venous was drawn; and (4) whole blood rather than plasma was assayed.

Participants with self-reported diabetes (48 type 1, 133 type 2 diabetes) did not undergo the glucose tolerance test and were excluded from these analyses. We also excluded participants with a blood glucose of $\geq 11.11 \mathrm{mmol} / 1(\geq 200$ $\mathrm{mg} / \mathrm{dl})(n=56)$, as they were likely to have diabetes [12], as well as those whose status could not be ascertained owing to missing data $(n=134)$.

Mortality follow-up until 30 September 2005 was conducted using the National Health Service Central Registry, with data available for $99.2 \%$ of men. We excluded 43 men whose cause of death was unknown and a further 48 men for whom data on categorical covariates were missing. Evidence from two areas suggests that data from death certificates are accurate. First, in a Scottish cohort [13], investigators examined the risk factors for stroke death (as recorded from death certificates) and non-fatal events (as ascertained from hospital admissions data). The latter can be regarded as a highly accurate method of ascertaining stroke, given that it is based on routine test procedures such as computed axial tomography ('CAT') scans. In these analyses, the risk factors for stroke mortality rates and stroke morbidity were the same, suggesting that death certificates do indeed provide valid information on cause. Second, in an autopsy study, cerebral stroke was found to be correctly recorded on death certificates in $84 \%$ of cases [14].

The present analyses are therefore based on 18,406 men (17,724 for whom data were complete, 682 for whom data values on missing continuous covariates were imputed). Preliminary analyses showed that the main increase in stroke mortality rates was above the 90th percentile of blood glucose distribution. We therefore partitioned the population into three equally sized groups below this point and four, progressively smaller, groups above it, enabling any differences in mortality rates either side of this inflection to be detected. Mortality rates in these groups were adjusted for age using 5-year age groups using the direct standardisation method, with the total study population as the standard. Using plots created by fitting restricted cubic regression splines that allow a wide range of nonlinear effects to be estimated [15], we visually inspected the shape of the relationship between blood glucose (continuous scale) and both stroke and all-cause mortality. Hazard ratios and accompanying CIs were computed using Cox's proportional hazards regression model with follow-up period as the time scale.

\section{Results}

During a maximum of 38 years of follow-up, there were 13,116 deaths, 1,189 of which were ascribed to stroke. Table 1 and visual inspection of the plots for stroke and allcause mortality against the continuous measure of blood glucose indicated that elevated mortality rates appeared to begin in the central blood glucose group (about $4.6 \mathrm{mmol} / \mathrm{l}$ ) and that the slope after this point could be adequately described using a single linear term. Below the blood glucose value of $4.6 \mathrm{mmol} / 1$ there was no apparent relationship between all-cause or stroke mortality rates and blood glucose. We therefore summarised the relationship between blood glucose and both stroke and all-cause mortality using a threshold model that matches previous analyses of the Whitehall study in which coronary heart disease was the outcome of interest [16]. A $1 \mathrm{mmol} / \mathrm{l}$ increase in blood glucose above the $4.6 \mathrm{mmol} / 1$ threshold was associated with a $27 \%$ increase in risk of death from stroke (hazard ratio $1.27,95 \%$ CI $1.14-1.42$ ) and a $16 \%$ increase in all-cause mortality $(1.16,1.12-1.20)$. These elevations in risk were unaffected by adjustment for employment grade, but were partially attenuated after controlling for other covariates both in the analyses featuring stroke $(1.17,1.04-1.31)$ and in those for total mortality $(1.09,1.05-1.13)$. 
Table 1 Hazard ratios (95\% CIs) for the relationship of post-challenge blood glucose with stroke and all-cause mortality rates: the original Whitehall study

\begin{tabular}{|c|c|c|c|c|c|c|c|c|}
\hline & \multicolumn{7}{|c|}{ Blood glucose $\left(\mathrm{mmol} / \mathrm{l}^{\mathrm{e}}\right)$} & \multirow{2}{*}{$\begin{array}{l}\text { Hazard ratio per } \\
1.0 \mathrm{mmol} / 1 \\
\text { increase above } \\
4.6 \mathrm{mmol} / 1 \\
\text { threshold }\end{array}$} \\
\hline & $2.50-3.78$ & $3.79-4.22$ & $4.23-4.94$ & $4.95-5.28$ & $5.29-5.72$ & $5.73-6.78$ & $6.79-11.10$ & \\
\hline $\begin{array}{l}\text { Population, } \\
n(\%)\end{array}$ & $5,663(31)$ & $5,469(30)$ & $5,390(29)$ & 825 (4) & $540(3)$ & $382(2)$ & $137(1)$ & $4,027(22)$ \\
\hline \multicolumn{9}{|c|}{ All-cause mortality } \\
\hline Deaths $(n)$ & 4,056 & 3,852 & 3,766 & 594 & 416 & 312 & 122 & 2,922 \\
\hline Mortality rate $^{\mathrm{a}}$ & 30.4 & 30.6 & 30.5 & 31.2 & 34.1 & 36.3 & 43.2 & - \\
\hline Model $\mathrm{A}^{\mathrm{b}}$ & 1.0 (ref) & $\begin{array}{l}1.00 \\
(0.96-1.04)\end{array}$ & $\begin{array}{l}1.01 \\
(0.95-1.07)\end{array}$ & $\begin{array}{l}1.04 \\
(0.96-1.14)\end{array}$ & $\begin{array}{l}1.17 \\
(1.06-1.29)\end{array}$ & $\begin{array}{l}1.32 \\
(1.18-1.49)\end{array}$ & $\begin{array}{l}1.63 \\
(1.36-1.95)\end{array}$ & $\begin{array}{l}1.16 \\
(1.12-1.20)\end{array}$ \\
\hline Model B ${ }^{c}$ & 1.0 & $\begin{array}{l}1.01 \\
(0.97-1.06)\end{array}$ & $\begin{array}{l}1.00 \\
(0.95-1.04)\end{array}$ & $\begin{array}{l}1.03 \\
(0.95-1.13)\end{array}$ & $\begin{array}{l}1.15 \\
(1.04-1.27)\end{array}$ & $\begin{array}{l}1.28 \\
(1.14-1.44)\end{array}$ & $\begin{array}{l}1.62 \\
(1.35-1.94)\end{array}$ & $\begin{array}{l}1.15 \\
(1.10-1.19)\end{array}$ \\
\hline Model C ${ }^{\mathrm{d}}$ & 1.0 & $\begin{array}{l}1.02 \\
(0.98-1.07)\end{array}$ & $\begin{array}{l}1.01 \\
(0.97-1.06)\end{array}$ & $\begin{array}{l}1.04 \\
(0.95-1.14)\end{array}$ & $\begin{array}{l}1.14 \\
(1.02-1.29)\end{array}$ & $\begin{array}{l}1.21 \\
(1.08-1.36)\end{array}$ & $\begin{array}{l}1.32 \\
(1.10-1.58)\end{array}$ & $\begin{array}{l}1.09 \\
(1.05-1.13)\end{array}$ \\
\hline \multicolumn{9}{|l|}{ Stroke mortality } \\
\hline Deaths $(n)$ & 358 & 345 & 335 & 64 & 44 & 29 & 14 & 274 \\
\hline Mortality rate ${ }^{\mathrm{a}}$ & 2.7 & 2.9 & 2.7 & 3.4 & 3.6 & 3.3 & 3.7 & - \\
\hline Model $\mathrm{A}^{\mathrm{b}}$ & 1.0 (ref) & $\begin{array}{l}1.04 \\
(0.90-1.21)\end{array}$ & $\begin{array}{l}1.02 \\
(0.88-1.19)\end{array}$ & $\begin{array}{l}1.30 \\
(1.00-1.70)\end{array}$ & $\begin{array}{l}1.44 \\
(1.06-1.98)\end{array}$ & $\begin{array}{l}1.45 \\
(0.99-2.11)\end{array}$ & $\begin{array}{l}2.25 \\
(1.32-3.83)\end{array}$ & $\begin{array}{l}1.27 \\
(1.14-1.42)\end{array}$ \\
\hline Model B ${ }^{c}$ & 1.0 & $\begin{array}{l}1.04 \\
(0.90-1.21)\end{array}$ & $\begin{array}{l}1.02 \\
(0.88-1.18)\end{array}$ & $\begin{array}{l}1.30 \\
(1.00-1.70)\end{array}$ & $\begin{array}{l}1.44 \\
(1.06-1.97)\end{array}$ & $\begin{array}{l}1.46 \\
(1.00-2.13)\end{array}$ & $\begin{array}{l}2.21 \\
(1.29-3.77)\end{array}$ & $\begin{array}{l}1.27 \\
(1.13-1.42)\end{array}$ \\
\hline Model $C^{\mathrm{d}}$ & 1.0 & $\begin{array}{l}1.04 \\
(0.90-1.21)\end{array}$ & $\begin{array}{l}1.02 \\
(0.88-1.19)\end{array}$ & $\begin{array}{l}1.27 \\
(0.97-1.66)\end{array}$ & $\begin{array}{l}1.37 \\
(1.00-1.87)\end{array}$ & $\begin{array}{l}1.24 \\
(0.85-1.82)\end{array}$ & $\begin{array}{l}1.76 \\
(1.02-3.02)\end{array}$ & $\begin{array}{l}1.17 \\
(1.04-1.31)\end{array}$ \\
\hline
\end{tabular}

Stroke deaths were coded according to the eighth, ninth (430-439 for both) or tenth revision (I60-I69) of the International Classification of Diseases

${ }^{a}$ Age-adjusted mortality rates are expressed per 1,000 person-years

${ }^{\mathrm{b}}$ Age-adjusted

${ }^{\mathrm{c}}$ Adjusted for age and employment grade

${ }^{\mathrm{d}}$ Adjusted for age, employment grade, disease at study entry, physical activity, smoking habit, marital status, forced expiratory volume in $1 \mathrm{~s}$ (height-adjusted), systolic blood pressure, diastolic blood pressure, height, body mass index (linear and quadratic terms) and plasma cholesterol e $1 \mathrm{mmol} / \mathrm{l}=18 \mathrm{mg} / 100 \mathrm{ml}$ ref, referent category

\section{Discussion}

To our knowledge, this is the largest study to date to examine the link between blood glucose and stroke mortality rates. We found an incremental increase in stroke risk above a glucose level of $4.6 \mathrm{mmol} / \mathrm{l}$ in a non-diabetic population of employed men. This is consistent with a previous report from the Whitehall study in which coronary heart disease mortality, an outcome with a similar pathophysiology to stroke, was the endpoint of interest [16]. Although attenuated, the association between blood glucose and stroke remained after control for a range of covariates, as it did for total mortality.

The present study has a number of strengths. These include: (1) cohort size, which offers higher statistical power than many others; (2) minimal loss to follow-up, thereby reducing the likelihood of selection bias; and (3) measurement of a range of physiological and behavioural covariates which permit consideration of confounding.
At the same time, our study is not without weaknesses. First, because blood glucose, confounders and mediators may fluctuate over time, it is preferable to have more than a single baseline measurement. In this regard, surviving members of the original Whitehall study have recently been re-surveyed; unfortunately, however, blood glucose was not measured. Second, we were not able to investigate the blood glucose-stroke mortality gradient in women, which might plausibly be of a different shape to that seen in men. Third, given the similarities in the pathophysiology of coronary heart disease and ischaemic stroke, a stronger relationship between blood glucose and the latter rather than between blood glucose and haemorrhagic stroke would be anticipated. However, as death certificates in the UK do not reliably identify stroke subtypes, we were unable to examine this hypothesis.

A fourth potential weakness is that some of the factors for which we controlled (such as blood pressure and body mass index) could be components of the same constellation 
of risk factors that is indicated by a raised post-load glucose level. The use of data from an occupational cohort represents a fifth problem, namely the issue of the generalisability our findings. In this respect, however, the fact that results for common risk factor-disease associations reported in the Whitehall study (e.g. blood pressure and obesity as predictors of cardiovascular disease) are very similar to those apparent in general population-based studies suggests that our results are indeed generalisable.

One final potential problem is that, as described, the post-challenge blood glucose test used in the Whitehall study at baseline in the 1960s is non-standard in comparison to present day protocols. The characteristics of this test explain why blood glucose levels found at baseline in the present study seem lower than expected, for instead of the $75 \mathrm{~g}$ glucose challenge employed today, a $50 \mathrm{~g}$ challenge was used. Moreover, to simplify data interpretation, we excluded men with a blood glucose of $\geq 11.11 \mathrm{mmol} / \mathrm{l}$, as they were deemed likely to have diabetes. It should also be noted that men in this cohort were surveyed in the 1960s when, due to the lower prevalence of obesity, diabetes and raised blood glucose were much less common than they are today. Following on from this, it is possible that the threshold we identified for an increased risk of total and stroke mortality is higher in more recently established cohorts that have used contemporary test procedures.

In conclusion, the incremental elevation in stroke and all-cause mortality rates occurring with increases in postchallenge blood glucose concentrations above a threshold of $4.6 \mathrm{mmol} / \mathrm{l}$ warrants further examination in large-scale studies, particularly in women.

Acknowledgements The original screening of the Whitehall study was funded by the Department of Health and Social Security and the Tobacco Research Council. D. Batty is a Wellcome Trust fellow, M. Marmot is a MRC Research Professor, M. Shipley is supported by the British Heart Foundation and M. Kivimaki is supported by the Academy of Finland.

Duality of interest The authors declare that there is no duality of interest associated with this manuscript.

Open Access This article is distributed under the terms of the Creative Commons Attribution Noncommercial License which permits any noncommercial use, distribution, and reproduction in any medium, provided the original author(s) and source are credited.

\section{References}

1. Wannamethee SG, Perry IJ, Shaper AG (1999) Nonfasting serum glucose and insulin concentrations and the risk of stroke. Stroke 30:1780-1786

2. Folsom AR, Rasmussen ML, Chambless LE et al (1999) Prospective associations of fasting insulin, body fat distribution, and diabetes with risk of ischemic stroke. The atherosclerosis risk in communities (ARIC) study investigators. Diabetes Care 22:1077-1083

3. Haheim LL, Holme I, Hjermann I, Leren P (1995) Nonfasting serum glucose and the risk of fatal stroke in diabetic and nondiabetic subjects. 18-year follow-up of the Oslo Study. Stroke 26:774-777

4. Hart CL, Hole DJ, Davey Smith G (1999) Risk factors and 20 -year stroke mortality in men and women in the Renfrew/Paisley study in Scotland. Stroke 30:1999-2007

5. Myint PK, Sinha S, Wareham NJ et al (2007) Glycated hemoglobin and risk of stroke in people without known diabetes in the European Prospective Investigation into Cancer (EPIC)Norfolk prospective population study: a threshold relationship? Stroke 38:271-275

6. DECODE Study Group - the European Diabetes Epidemiology Group (2001) Glucose tolerance and cardiovascular mortality: comparison of fasting and 2-hour diagnostic criteria. Arch Intern Med 161:397-405

7. Fuller JH, Shipley MJ, Rose G, Jarrett RJ, Keen H (1983) Mortality from coronary heart disease and stroke in relation to degree of glycaemia: the Whitehall study. BMJ 287:867-870

8. Reid DD, Hamilton PJS, McCartney P et al (1974) Cardiorespiratory disease and diabetes among middle-aged male civil servants. Lancet 1:469-473

9. Pan WH, Cedres LB, Liu K et al (1986) Relationship of clinical diabetes and asymptomatic hyperglycemia to risk of coronary heart disease mortality in men and women. Am J Epidemiol 123:504-516

10. Yano K, Kagan A, McGee D, Rhoads GG (1982) Glucose intolerance and nine-year mortality in Japanese men in Hawaii. Am J Med 72:71-80

11. Jarrett RJ, Keen H, McCartney M et al (1978) Glucose tolerance and blood pressure in two population samples: their relation to diabetes mellitus and hypertension. Int J Epidemiol 7:15-24

12. Fuller JH, Shipley MJ, Rose G, Jarrett RJ, Keen H (1980) Coronary-heart-disease risk and impaired glucose tolerance. The Whitehall study. Lancet 1:1373-1376

13. Hart CL, Hole DJ, Davey Smith G (2000) Comparison of risk factors for stroke incidence and stroke mortality in 20 years of follow-up in men and women in the Renfrew/Paisley Study in Scotland. Stroke 31:1893-1896

14. Hasuo Y, Ueda K, Kiyohara Y et al (1989) Accuracy of diagnosis on death certificates for underlying causes of death in a long-term autopsy-based population study in Hisayama, Japan; with special reference to cardiovascular diseases. J Clin Epidemiol 42:577-584

15. Durrleman S, Simon R (1989) Flexible regression models with cubic splines. Stat Med 8:551-561

16. Brunner EJ, Shipley MJ, Witte DR, Fuller JH, Marmot MG (2006) Relation between blood glucose and coronary mortality over 33 years in the Whitehall Study. Diabetes Care 29:26-31 